OPEN ACCESS

Edited by:

Maria Jesus Moreno-Aliaga, University of Navarra, Spain

Reviewed by: Lushen Li,

University of Maryland, Baltimore

United States

Lucia Conti,

Istituto Superiore di Sanità (ISS), Italy

*Correspondence:

Stefania Miccade

stefania.miccadei@ifo.gov.it

Specialty section:

This article was submitted to Nutritional Immunology, a section of the journal

Frontiers in Immunology

Received: 08 August 2018 Accepted: 19 March 2019

Published: 11 April 2019

Citation:

Mileo AM, Nisticò $P$ and Miccadei S

(2019) Polyphenols:

Immunomodulatory and Therapeutic

Implication in Colorectal Cancer.

Front. Immunol. 10:729

doi: 10.3389/fimmu.2019.00729

\section{Polyphenols: Immunomodulatory and Therapeutic Implication in Colorectal Cancer}

\author{
Anna Maria Mileo, Paola Nisticò and Stefania Miccadei* \\ Tumor Immunology and Immunotherapy Unit, Department of Research, Advanced Diagnostic and Technological Innovation, \\ IRCCS Regina Elena National Cancer Institute, Rome, Italy
}

Polyphenolic compounds, widely present in fruits, vegetables, and cereals, have potential benefits for human health and are protective agents against the development of chronic/degenerative diseases including cancer. More recently these bioactive molecules have been gaining great interest as anti-inflammatory and immunomodulatory agents, mainly in neoplasia where the pro-inflammatory context might promote carcinogenesis. Colorectal cancer $(\mathrm{CRC})$ is considered a major public healthy issue, a leading cause of cancer mortality and morbidity worldwide. Epidemiological, pre-clinical and clinical investigations have consistently highlighted important relationships between large bowel inflammation, gut microbiota (GM), and colon carcinogenesis. Many experimental studies and clinical evidence suggest that polyphenols have a relevant role in CRC chemoprevention, exhibit cytotoxic capability vs. CRC cells and induce increased sensitization to chemo/radiotherapies. These effects are most likely related to the immunomodulatory properties of polyphenols able to modulate cytokine and chemokine production and activation of immune cells. In this review we summarize recent advancements on immunomodulatory activities of polyphenols and their ability to counteract the inflammatory tumor microenvironment. We focus on potential role of natural polyphenols in increasing the cell sensitivity to colon cancer therapies, highlighting the polyphenol-based combined treatments as innovative immunomodulatory strategies to inhibit the growth of CRC.

Keywords: polyphenols, immunomodulation, inflammation, gut microbiota, colorectal cancer, colorectal cancer therapy

\section{INTRODUCTION}

Colorectal cancer is the world's second deadliest cancer after lung (1), more than half (55\%) of the cases of CRC occur in developed regions, but developing countries are catching up. As their economies grow, so does the incidence of colorectal cancer. The scientific data show that no correct dietary habits and life style may affect the risk/progression of inflammation-related disease such as CRC (2-8). In inflammatory bowel disease (IBD) chronic inflammation leads to mucosal disruption accompanied by an excessive production of reactive oxygen species (ROS) (9) and may promote cancer onset, progression and metastatic diffusion (10). Apart from IBD, inflammation-related cancer risk factors are high fat/low fiber diet, obesity, and family history of CRC, all linked to an abnormal gut microbial composition (11-14). In sporadic (no-colitis-associated) CRC genetic alterations, such as adenomatous polyposis coli (Apc) mutations, DNA mismatch repair (MMR) 
deficiency, and microsatellite instability (MSI) are reported (15). Immune microenvironment of MSI primary colon cancer revealed a high infiltration of activated CD8 + CTL (16) and high expression of immune checkpoints, indicating that this subgroup of tumors may represent a target of immune checkpoint blockade (ICB). These results stem from seminal data by Galon et al. demonstrating that the lymphocyte infiltration in the primary CRC is a good prognostic factor (17). Clinical and experimental studies have focused on the complex and essential role of immune responses in CRC. In this scenario the crucial role of gut microbiota in triggering chemokine production leading to $\mathrm{T}$ cell recruitment in tumor tissues has been demonstrated (18). Notably dietary bioactive compounds act as anti-tumor agents $(19,20)$ modulating several molecular targets involved in survival, proliferation, angiogenesis, invasion and metastasis in cancer (21-23). As such several nutrients (24) may affect crucial inflammatory chemokines and cytokines which strongly contribute to the epithelial-mesenchymal transition program involved in cancer invasion, metastasis, and immune escape process (25) also in CRC (26).

Among bioactive compounds, polyphenols are known as potential anti-inflammatory and anti-tumor agents (Figure 1) and could be good candidates for cancer prevention and treatment (27-29) targeting key molecular pathways involved in colorectal cancer (30-32).

Epidemiological studies suggest that the Mediterranean Diet (MD) rich in polyphenols, could reduce level of inflammation and oxidative damage and has linked with a relevant reduction in cancer risk mainly in $\operatorname{CRC}(33,34)$.

Considering the role of inflammation in CRC, antiinflammatory agents such as polyphenols are promising drugs for less toxic clinical intervention. In this review we detail the polyphenol properties, most likely related to their immunomodulatory activities, able to counteract several aspects of the inflammatory process in tumor microenvironment through the modulation of cytokine and chemokine production and in turn immune cell activation (35).

\section{DIETARY POLYPHENOLS}

Polyphenols are a large group of compounds synthesized by plants for a variety of functions, such as protection against UV radiation, mechanical damage, and microbial infection (36). Different classes and subclasses of polyphenols generate a large structural variability as a function of their number of phenol rings in combination with one or more hydroxyl compounds (37). Polyphenols present in fruits, vegetables, and cereals have emerged as one of the main families of natural compounds, most of them have been considered functional foods with potential biological activities in many pathologies, such as cancer (38-40), diabetes (41), obesity and inflammation-related diseases (42-44), neurodegenerative disorders $(45,46)$, and cardiovascular diseases (47). The main groups of dietary polyphenols promoting beneficial effects on human health are: phenolic acids, flavonoids, stilbenes, and lignans (see http://phenol-explorer.eu/compounds/classification for an update classification).
They are potential anti-inflammatory and anti-cancer agents, especially in anatomical districts such as colon, where the activity of dietary bioactive compounds is relevant.

\section{Cross Talk Between Polyphenols and Gut Microbiota}

After oral assumption, dietary polyphenols are recognized by the human body as xenobiotics and only a small amount is hydrolyzed in active compounds and absorbed in the small intestine (48). The remaining polyphenols accumulate in the large intestinal lumen where they might be hydrolyzed by the enzymatic activities of the gut microbial community into various metabolites before absorption. It is becoming clear that the GM, after degradation of food macromolecules (49), plays a crucial role in the maturation, development, and function of the host immune system $(18,50-52)$. Nevertheless, a continuous dialogue between microbiota and innate and adaptive immunity (53) regulates intestinal tissue homeostasis. When this functional control is lost, dysbiosis occurs leading to inflammatory disorders that might promote tumorigenesis (54-58).

Recently, advances in defining the effects of the microbiota on polyphenol bioavailability and function have been made. Moreover, it has been recognized that polyphenol-rich foods can affect the composition and activity of the microbiota $(59,60)$. Dietary polyphenols exert a prebiotic-like effect, contribute to maintain the gut health and to reduce levels of inflammation through the stimulation of beneficial bacteria growth and inhibition of pathogenic microbe development $(61,62)$. The large inter-individual variation of metabolites (30) can be related, at least partly, to differences in the GM composition and therefore in the way the polyphenols are catabolized.

Epidemiological data $(33,63)$ are concordant in suggesting that the adherence to MD decreases the risk of a variety of cancers. The polyphenol-rich MD modulates multiple processes involved in inflammatory response and carcinogenesis, such as free radical production, nuclear factor kappa-light-chainenhancer of activated $\mathrm{B}$ cells $(\mathrm{NF}-\kappa \mathrm{B})$ activation, and the eicosanoid-derived pathways. Thus, an appropriate diet can maintain the equilibrium between the inflammatory pathway and the anti-inflammatory process induced by many dietary compounds including polyphenols (64). Furthermore, great attention has been addressed to the effect that MD has on maintenance of "good" GM (65) and on control of carcinogenesis through specific epigenetic alterations (66).

Recently, the association between microbiota and different stages of CRC and the role of microbiota in the therapeutic response including that of the immune checkpoint-blocking therapy has shown to be highly relevant (67).

\section{Polyphenols as Immunomodulatory Agents}

Growing evidence clearly indicates that diet influences the innate and adaptive arms of the immune system (Figure 1) (68). Innate immune cells, such as macrophages, myeloidderived suppressor, dendritic and natural killer cells and adaptive immune cells ( $\mathrm{T}$ and $\mathrm{B}$ lymphocytes) may infiltrate the tumor tissues impacting the immune microenvironment and the clinical outcome (49). Several investigations have reported the antitumor 


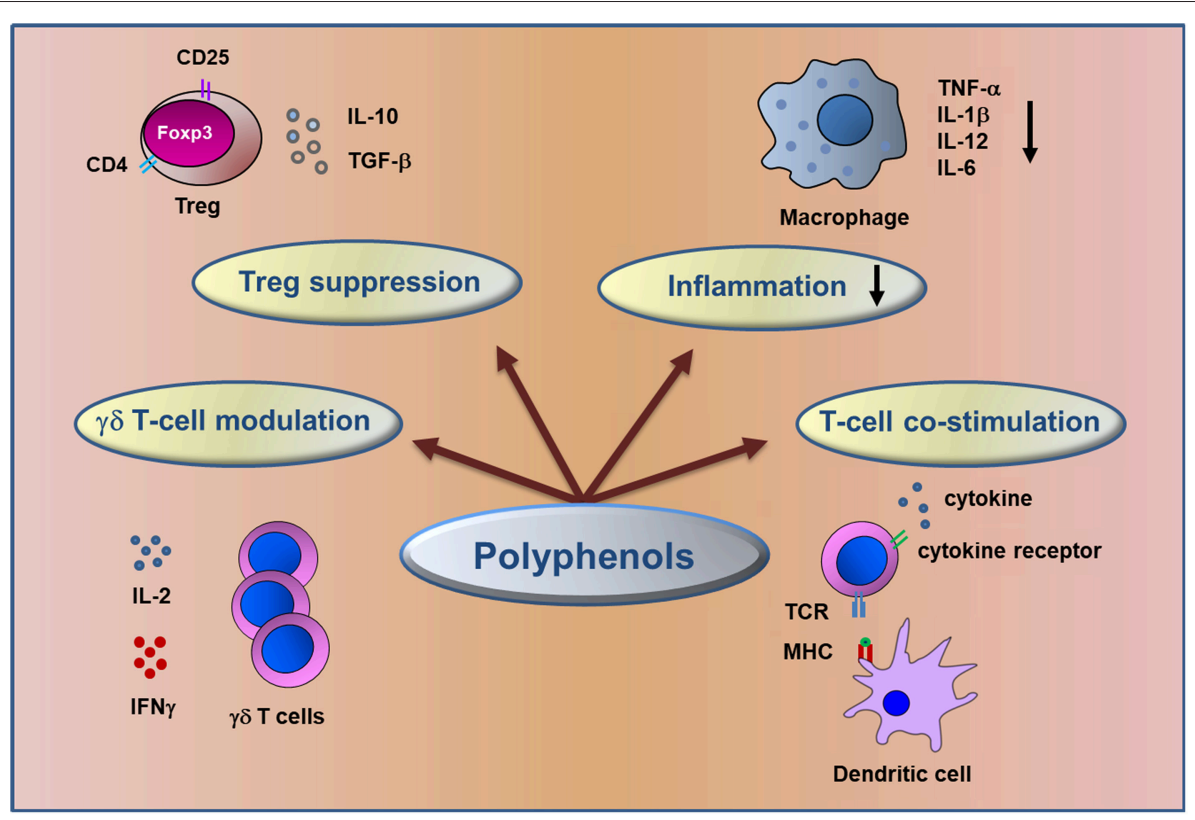

FIGURE 1 | Schematic representation of immunomodulatory action of dietary polyphenols. The figure summarizes the major mechanisms involved in the control of inflammation and in anti-tumor immune response elicited by polyphenols in CRC.

effect of polyphenols through the modulation of T lymphocyte functionality to recognize and lyse tumor cells enhancing the immune response and counteracting the immune escape, a cancer progression hallmark $(69,70)$.

Among polyphenol studies, the dose dependent therapeutic efficacy of resveratrol has been demonstrated in an animal model of ulcerative colitis. Resveratrol, a flavonoid stilbene compound, treatment is associated with the regulation of $\mathrm{T}$ regulatory (Treg)/T helper 17 (Th17) balance and the level of plasma and intestinal mucosal cytokines including interleukin 10 (IL-10), transforming growth factor-beta1 (TGF- $\beta 1$ ), interleukin 6 (IL-6), and interleukin 17 (IL-17) (71).

Curcumin, a no-flavonoid compound, suppressed the development of Dextran Sulfate Sodium (DSS)-induced colitis in a mouse model through the inhibition of NF- $\kappa \mathrm{B}$ activation and the induction of mucosal Treg cells. Treatment with nanoparticles of curcumin induced an alteration of the gut microbial structure and a change in the level of fecal short chain fatty acids, indicating nanoparticles curcumin as a therapeutic option for the treatment of IBD diseases (72).

Trans-Scirpusin A (TSA), a resveratrol oligomer, has been reported to inhibit the growth of colorectal cancer in in vivo model. Among different mechanisms involved in its antitumor efficacy, TSA overcomes the tumor-associated immunosuppressive microenvironment by reducing the number of CD25-FoxP3 regulatory $\mathrm{T}$ cells and myeloid-derived suppressor cells (73).

Dietary anti-inflammatory polyphenols, such as chlorogenic acid and resveratrol, significantly suppressed the secretion of several cytokines (interferon gamma IFN $-\gamma$, tumor necrosis factor alfa TNF- $\alpha$ ), reduced the colonic infiltration of $\mathrm{CD}^{+} \mathrm{T}$ cells producing these cytokines and neutrophils in colitis and in colitis-associated to CRC experimental model $(74,75)$. In mouse $\mathrm{C} 57 \mathrm{BL} / 6 \mathrm{~J}-\mathrm{Min} /^{+}$, bearing a germline Apc mutation, a classical model of familial adenomatous polyposis (FAP) and sporadic colorectal cancer, administration of curcumin increases mucosal $\mathrm{CD}^{+} \mathrm{T}$ and $\mathrm{B}$ cells and contributes to prevent adenoma formation (76). Apple polyphenolic extracts (77), soy and sulforaphane flavonoid compounds $(78,79)$ reduce proinflammatory cytokine expression (IL-1 $\beta$, TNF- $\alpha$, IL-6, IL-17, and IFN- $\gamma$ ) in the context of a chemically induced colitis. The immunomodulatory activity of cocoa, a flavonoid compound, has been demonstrated to affect the gut immune responses in young rats by increasing the percentage of $\gamma \delta \mathrm{T}$ cells and lowering the effect of IgA (80).

It has been demonstrated an important role of chemokine receptor 3 (CXCR3) and its ligands in both inflammation and colorectal cancer (81). Recently it has been shown that resveratrol trihydroxy trans stilbene (TS) is able to hamper the suppressive ability of Treg by increasing CXCR3 in CD8+ Tregs facilitating Teff recruitment with a reduction of number and size of tumors (82). Dendritic cells (DCs) play a relevant role in cancer by exerting both pro-tumorigenic and antitumorigenic functions depending on the local environment (83) having an impact upon clinical outcome in CRC patients (84). Furthermore, Kajihara et al. analyzed the potential role of a dendritic-based cancer immunotherapy treatment in patients with recurrent or metastatic CRC (85). The potential effects of polyphenols on the function of DCs, the most effective antigenpresenting cells, with the capacity to shift immune response toward tolerance or immune activation $(86,87)$ has been highlighted in different studies. In particular protocatechuic acid, 
an anthocyanin flavonoid metabolite, has been demonstrated to have a main regulatory effect on the functional activation of DCs, suggesting the potential therapeutic application of this dietary compound against inflammatory conditions (88).

Quercetin and piperine, a flavonoid and no-flavonoid compound, when combined represent an effective and potent anti-inflammatory strategy to treat acute colitis in mice. This anti-inflammatory effect was mediated by impaired DC immune responses (89). Moreover, quercetin has been shown to suppress the secretion of TNF- $\alpha$ and interfere with the onset of IBD (90).

\section{Polyphenols and Inflammation}

Chronic inflammation characterized by the continuous presence of inflammatory cells and inflammatory mediators is known to play a key role in the development of various cancers. A longstanding chronic inflammation is a key predisposing factor of CRC in IBD since an excessive ROS production present in the inflamed mucosa alters important cellular functions and damages intestinal mucosa (91-93).

For several years, polyphenols have been extensively studied for their ability to scavenge free-radicals endogenously generated (94) or formed by radiation and xenobiotics (95).

Polyphenols have anti-inflammatory effect and their antioxidant properties are mainly mediated by ability to down-regulate the nuclear factor NF- $k \mathrm{~B}$, modulating crucial cell signaling pathways involved in inflammation and cancer (96-100).

Evaluating the polyphenolic fraction of olive oil, a principal component of $\mathrm{MD}$, Serra et al. reported the inhibition of some crucial colonic inflammatory processes mediated by NF- $k \mathrm{~B}$, inducible nitric oxide synthases (iNOS), IL-8 and IL-6, thus proposing olive oil as a major dietary compound able to prevent and counteract the progression of IBD (101).

Green tea polyphenols ameliorate antioxidant response, decrease inflammatory markers (TNF- $\alpha$, IL-6, and serum amyloid A), attenuate the pathological lesions and preserve colonic microstructure in a similar manner of sulfasalazine, the standard-of-care agent in IBD as shown in DSS mice (102). Several studies have demonstrated that cocoa exhibits a potential anti-inflammatory effects in in vitro and in vivo CRC models and might be a promising dietary preventive compound. Experiments performed in TNF- $\alpha$ stimulated colon cancer Caco-2 cells demonstrated that cocoa polyphenols downregulate inflammatory marker expression by suppressing NF$k \mathrm{~B}$ nuclear translocation and c-Jun $\mathrm{N}$-terminal kinase (JNK) phosphorylation. A cocoa-rich diet decreased the nuclear level of NF- $k \mathrm{~B}$ and the expression of cyclooxigenase-2 (COX-2) and nitric oxide (NO) synthase pro-inflammatory enzymes, in a colon carcinogenic rat model $(98,99)$. Moreover, recent findings demonstrated that cocoa suppresses the development of colitis-associated tumorigenesis by modulating NF- $k B / \mathrm{IL}-$ 6/Signal transducer and activator of transcription 3 (STAT3) signaling pathways and also induces apoptosis by activating caspase-3 in a mouse model (103).

Evidence has been provided that pomegranate phenolic extract (PE) and/or its microbiota derived metabolite-urolithinA (UROA), have antioxidant, anti-inflammatory, and anticancer properties as showed by Larrosa et al. (104). They demonstrated that pomegranate could prevent colon inflammation before and during colitis disease in rats. PE and UROA decreased inflammation markers ( $i$ NOS, COX-2, prostaglandin E synthase, and prostaglandin E2) in colonic mucosa and could have a beneficial effect on the gut microbiota.

Flavanol extract from Chaenomeles japonica, a Japanese fruit, inhibited COX-2, matrix metalloproteinase-9 (MMP-9), and NF$k \mathrm{~B}$ expression indicating a cytotoxic anti-inflammatory and antimetastatic activities toward the colon cancer SW-480 cells (105).

A recent study has shown that sugarcane extracts, containing a potent reservoir of polyphenols, provide anti-inflammatory activity by decreasing NF- $k$ B phosphorylation and subsequently reduced expression of IL-8 signaling in lipopolysaccharidestimulated colon cancer cells (106).

Edible mushroom (Pleurotus eryngii), rich in polyphenols, has been shown to inhibit the production of pro-inflammatory molecules, such as ROS and NO in RAW264.7 macrophage cell line and to induce an anti-proliferative effect on HCT116 colon cancer cells (107). All these results indicate the relevance of dietary polyphenol intake derived from food throughout the world.

The consumption of many varieties of plant derivatives is very ancient remedy against all kinds of ailments. Since ancient times folk medicine has made use of plants like Opuntia ficus indica and Ceratonia Siliqua and recently their polyphenolic extracts have received much attention for their antioxidant, anti-inflammatory, immunomodulatory and anticancer properties. Aboura et al. demonstrated the protective effects of polyphenol-rich infusions from C. Siliqua leaves on inflammation either in in vitro and in vivo experimental models, reducing pro-inflammatory cytokine expression (such as TNF- $\alpha$, IL-1 $\beta$, and IL-6), and NO production (108). The anti-inflammatory activity of Garcinia Kola (109) and Ocimum Gratissimum (110) polyphenolic extracts is exerted by reducing TNF- $\alpha$ and pro-inflammatory cytokine production in a rat colitis experimental model.

\section{Potential Role of Polyphenols in CRC Prevention and Therapy}

Decades of research on bioactive compounds have highlighted the beneficial effects of anti-inflammatory polyphenols not only in preventing cancer, but also in potentiating the efficacy of chemo/radiotherapy and reducing the risk of tumor recurrence (111).

Primary prevention of colon cancer, using dietary agents, boasts a widespread use in healthy populations (112) and in IBD patients at high risk of developing CRC (113).

Protective effects of apple and berry fruits against colon cancer have been demonstrated in in vivo studies. The Apc Min+ mouse model has been used to show the chemopreventive effects of Annurca apple polyphenol extract, which decreased polyp numbers and size, in animals fed a balanced-diet and also counteracted the tumorigenic effect of a diet rich in fats (114).

The chemopreventive effect of black raspberries (BRB) in DSS-mice was mediated by the downregulation of the proinflammatory cytokine expression including TNF- $\alpha$ and IL- $1 \beta$ 
(115) and the decrease of COX-2 and plasma prostaglandin E2 levels. Furthermore, Pan et al. performed a comprehensive analysis of BRB metabolic profiles correlated with a decrease of polyp number and size in Apc ${ }^{\mathrm{Min}+}$ mice (116).

Consistent with the well-known antioxidant and antiinflammatory properties of resveratrol (117) Cui et al. reported a decrease of colon inflammation score through the down regulation of mucosal and/or systemic TNF- $\alpha$ and IFN- $\gamma$ expression in a mouse model of colitis (75). IL-10-deficient mouse, a well-documented model for colitisassociated cancer, was used to investigate the chemopreventive properties of curcumin which has been shown to have antiinflammatory, anti-oxidative and anti-proliferative properties. The chemopreventive effect of curcumin reduced colonic tumor burden and was associated with the maintenance of a high microbial diversity (118).

Polyphenols may also behave as pro-oxidants (119, 120), triggering ROS-mediated cancer cell death $(121,122)$, affecting tumor cell behavior based on differential redox status of cancer cells comparing with normal ones (123). Cocoplum (Chrysobalanus icaco L.) anthocyanin-rich tropical fruit exerts anti-inflammatory activity through the reduction of TNF- $\alpha$, IL$1 \beta$, IL-6, and NF- $\kappa$ B expressions and pro-oxidant effect on HT-29 human colorectal adenocarcinoma cells (124).

Conventional radio/chemotherapeutic treatment may induce immunogenic cell death (ICD), essential for activation of a $\mathrm{T}$ cell dependent immune response specific for dead cell-derived antigens. The improved efficacy of cancer therapy when tumor cells undergo an ICD (125-127) leads to the stimulation of $\mathrm{T}$ cells by $\mathrm{DC}$ through capture, processing, and presentation of antigens to naïve $\mathrm{CD} 4^{+}$and $\mathrm{CD} 8^{+} \mathrm{T}$ cells, which in turn elicit an antitumor response (128). In CRC patients clinical applications of therapeutic drugs have been greatly restricted due to the acquired chemoresistance as well as side-effect toxicity (129). These limitations highlight the need for development of novel anti-tumor strategies that may enhance chemosensitivity of tumor cells and reduce toxicity (130).

The concept of combined therapy of anti-cancer drugs with natural compounds has become a very promising approach in designing effective clinical trials. Evidence is emerging that conventional chemotherapy in CRC significantly benefits through combined treatment with some natural dietary polyphenols (131-135). Indeed several studies have demonstrated the effective and enhanced anticancer activity of 5 -Fluorouracil (5-FU) in combination with natural compounds and suggested the possibility of reducing dose-related toxicity and resistance to this drug $(136,137)$. This effect has been demonstrated by Hakim et al. who combined treatment of Gelam honey and ginger (Zingiber officinale) phenolic acid rich-extracts to enhance the chemotherapeutic effect of 5-FU against a colon adenocarcinoma cell line (138).

In recent years several studies have demonstrated the presence and the relevance of cancer stem cells (CSC) in different tumors including CRC (139-141). These cells are hypothesized to be responsible for tumor relapse and resistance to conventional therapies. Novel anticancer strategies have been designed to selectively target CSC and in this scenario natural polyphenols might have a relevant role.

Shakibaei et al. illustrated interesting effects of curcumin in enhancing chemosensitization to 5-FU-based chemotherapy by targeting the CSC subpopulation (142). Dietary bioactive polyphenolic metabolites derived from pomegranate and berries reduced the number and size of CSC colonspheres and modulated chemotherapy resistance (143).

Given that gastrointestinal cancer cells are poorly responsive to ionizing radiation treatment, novel radiosensitizer agents are required to improve the efficacy of CRC radiotherapy. Fisetin, a dietary flavonoid, has been demonstrated to enhance the radiosensitivity of p53-mutant HT-29 human colorectal cancer cells by increasing radiation induced DNA double strand breaks (144).

\section{CONCLUSIONS}

The current review reports recent epidemiological and experimental data supporting the bright future of dietary polyphenols as chemopreventive, anti-inflammatory, immunomodulatory, and anticancer agents in CRC (Figure 1). The polyphenol-rich diet not only may represent a chemopreventive treatment but also has important function on immune system by promoting symbiont and commensal bacterial populations, increases reciprocal interaction between host and microbiota which in turn have important effects on immune function Evidence underlines the use of polyphenols as sensitizers of chemo/radiotherapies paving the way for new combined strategies able to minimize toxicity and side effects of conventional treatment in oncological patients. In the new era of precision medicine it would be important to consider the oxidative status prior to polyphenol supplementation or dietary advice. Recent advance in metabolomics might reveal individual oxidative bio-signatures of cancer patients leading to a personalized treatment approach.

Further studies are needed to deeply evaluate the immunomodulatory role of polyphenols to improve the efficacy of novel treatment such as immune checkpoint blockade, a new reality in oncology.

\section{AUTHOR CONTRIBUTIONS}

SM and AM have made a substantial, direct and intellectual contribution to the article designing. PN contributed to the writing and revised the article. All authors have reviewed and approved the final version of the manuscript for publication.

\section{FUNDING}

PN is supported by AIRC (IG \#19822; $5 \times$ mille \#12182).

\section{ACKNOWLEDGMENTS}

We apologize to those authors whose work could not be cited due to a space limitation. 


\section{REFERENCES}

1. Bray F, Ferlay J, Soerjomataram I, Siegel RL, Torre LA, Jemal A. Global cancer statistics 2018: GLOBOCAN estimates of incidence and mortality worldwide for 36 cancers in 185 countries. CA Cancer J Clin. (2018) 68:394-424. doi: $10.3322 /$ caac. 21492

2. Montenegro MF, Sanchez-del-Campo L, Fernandez-Perez MP, SaezAyala M, Cabezas-Herrera J, Rodriguez-Lopez JN. Targeting the epigenetic machinery of cancer cells. Oncogene. (2015) 34:135-43. doi: 10.1038/onc.2013.605

3. Sapienza C, Issa JP. Diet, nutrition, and cancer epigenetics. Annu Rev Nutr. (2016) 36:665-81. doi: 10.1146/annurev-nutr-121415-112634

4. Bishop KS, Ferguson LR. The interaction between epigenetics, nutrition and the development of cancer. Nutrients. (2015) 7:922-47. doi: $10.3390 /$ nu7020922

5. Aggarwal BB, Danda D, Gupta S, Gehlot P. Models for prevention and treatment of cancer: problems vs promises. Biochem Pharmacol. (2009) 78:1083-94. doi: 10.1016/j.bcp.2009.05.027

6. Lavalette C, Adjibade M, Srour B, Sellem L, Fiolet T, Hercberg S, et al. Cancer-specific and general nutritional scores and cancer risk: results from the prospective nutrinet-sante cohort. Cancer Res. (2018) 78:4427-35. doi: 10.1158/0008-5472.CAN-18-0155

7. Vineis $\mathrm{P}$, Wild CP. Global cancer patterns: causes and prevention. Lancet. (2014) 383:549-57. doi: 10.1016/S0140-6736(13)62224-2

8. Mantovani A, Allavena P, Sica A, Balkwill F. Cancer-related inflammation. Nature. (2008) 454:436-44. doi: 10.1038/nature07205

9. Rogler G. Chronic ulcerative colitis and colorectal cancer. Cancer Lett. (2014) 345:235-41. doi: 10.1016/j.canlet.2013.07.032

10. Hanahan D, Weinberg RA. Hallmarks of cancer: the next generation. Cell. (2011) 144:646-74. doi: 10.1016/j.cell.2011.02.013

11. Morrison DS, Parr CL, Lam TH, Ueshima H, Kim HC, Jee SH, et al. Behavioural and metabolic risk factors for mortality from colon and rectum cancer: analysis of data from the Asia-Pacific Cohort Studies Collaboration. Asian Pac J Cancer Prev. (2013) 14:1083-7. doi: 10.7314/APJCP.2013.14.2.1083

12. Dabritz J, Menheniott TR. Linking immunity, epigenetics, and cancer in inflammatory bowel disease. Inflamm Bowel Dis. (2014) 20:1638-54. doi: 10.1097/MIB.0000000000000063

13. Favoriti P, Carbone G, Greco M, Pirozzi F, Pirozzi RE, Corcione F. Worldwide burden of colorectal cancer: a review. Updates Surg. (2016) 68:7-11. doi: 10.1007/s13304-016-0359-y

14. Belkaid Y, Harrison OJ. Homeostatic immunity and the microbiota. Immunity. (2017) 46:562-76. doi: 10.1016/j.immuni.2017.04.008

15. Raskov H, Pommergaard HC, Burcharth J, Rosenberg J. Colorectal carcinogenesis-update and perspectives. World J Gastroenterol. (2014) 20:18151-64. doi: 10.3748/wjg.v20.i48.18151

16. Llosa NJ, Cruise M, Tam A, Wicks EC, Hechenbleikner EM, Taube JM, et al. The vigorous immune microenvironment of microsatellite instable colon cancer is balanced by multiple counter-inhibitory checkpoints. Cancer Discov. (2015) 5:43-51. doi: 10.1158/2159-8290.CD-14-0863

17. Galon J, Costes A, Sanchez-Cabo F, Kirilovsky A, Mlecnik B, LagorcePages C, et al. Type, density, and location of immune cells within human colorectal tumors predict clinical outcome. Science. (2006) 313:1960-4. doi: $10.1126 /$ science. 1129139

18. Roy S, Trinchieri G. Microbiota: a key orchestrator of cancer therapy. Nat Rev Cancer. (2017) 17:271-85. doi: 10.1038/nrc.2017.13

19. Sung B, Prasad S, Yadav VR, Lavasanifar A, Aggarwal BB. Cancer and diet: how are they related? Free Radic Res. (2011) 45:864-79. doi: 10.3109/10715762.2011.582869

20. Bishayee A, Sethi G. Bioactive natural products in cancer prevention and therapy: progress and promise. Semin Cancer Biol. (2016) 40-41:1-13. doi: 10.1016/j.semcancer.2016.08.006

21. Colotta F, Allavena P, Sica A, Garlanda C, Mantovani A. Cancer-related inflammation, the seventh hallmark of cancer: links to genetic instability. Carcinogenesis. (2009) 30:1073-81. doi: 10.1093/carcin/bgp127

22. Inacio Pinto N, Carnier J, Oyama LM, Otoch JP, Alcantara PS, Tokeshi F, et al. Cancer as a proinflammatory environment: metastasis and cachexia. Mediat Inflamm. (2015) 2015:791060. doi: 10.1155/2015/791060
23. Grivennikov SI, Greten FR, Karin M. Immunity, inflammation, and cancer. Cell. (2010) 140:883-99. doi: 10.1016/j.cell.2010.01.025

24. Sauer S, Plauth A. Health-beneficial nutraceuticals-myth or reality? Appl Microbiol Biotechnol. (2017) 101:951-61. doi: 10.1007/s00253-016-8068-5

25. Sistigu A, Di Modugno F, Manic G, Nistico P. Deciphering the loop of epithelial-mesenchymal transition, inflammatory cytokines and cancer immunoediting. Cytokine Growth Factor Rev. (2017) 36:67-77. doi: 10.1016/j.cytogfr.2017.05.008

26. Becht E, de Reynies A, Giraldo NA, Pilati C, Buttard B, Lacroix L, et al. Immune and stromal classification of colorectal cancer is associated with molecular subtypes and relevant for precision immunotherapy. Clin Cancer Res. (2016) 22:4057-66. doi: 10.1158/1078-0432.CCR-15-2879

27. Chikara S, Nagaprashantha LD, Singhal J, Horne D, Awasthi S, Singhal SS. Oxidative stress and dietary phytochemicals: role in cancer chemoprevention and treatment. Cancer Lett. (2018) 413:122-34. doi: 10.1016/j.canlet.2017.11.002

28. Yang CS, Wang X, Lu G, Picinich SC. Cancer prevention by tea: animal studies, molecular mechanisms and human relevance. Nat Rev Cancer. (2009) 9:429-39. doi: 10.1038/nrc2641

29. Elshaer M, Chen Y, Wang XJ, Tang X. Resveratrol: an overview of its anti-cancer mechanisms. Life Sci. (2018) 207:3409. doi: 10.1016/j.lfs.2018. 06.028

30. Alam MN, Almoyad M, Huq F. Polyphenols in colorectal cancer: current state of knowledge including clinical trials and molecular mechanism of action. Biomed Res Int. (2018) 2018:4154185. doi: 10.1155/2018/4154185

31. Tse G, Eslick GD. Cruciferous vegetables and risk of colorectal neoplasms: a systematic review and meta-analysis. Nutr Cancer. (2014) 66:128-39. doi: 10.1080/01635581.2014.852686

32. Shafiee G, Saidijam M, Tavilani H, Ghasemkhani N, Khodadadi I. Genistein induces apoptosis and inhibits proliferation of HT29 colon cancer cells. Int $J$ Mol Cell Med. (2016) 5:178-91. doi: 10.22088/acadpub.bums.5.3.178

33. Schwingshackl L, Hoffmann G. Adherence to Mediterranean diet and risk of cancer: a systematic review and meta-analysis of observational studies. Int $J$ Cancer. (2014) 135:1884-97. doi: 10.1002/ijc.28824

34. Schwingshackl L, Schwedhelm C, Galbete C, Hoffmann G. Adherence to mediterranean diet and risk of cancer: an updated systematic review and meta-analysis. Nutrients. (2017) 9:10. doi: 10.3390/nu9101063

35. Ghiringhelli F, Rebe C, Hichami A, Delmas D. Immunomodulation and antiinflammatory roles of polyphenols as anticancer agents. Anticancer Agents Med Chem. (2012) 12:852-73. doi: 10.2174/187152012802650048

36. Watson RR. Polyphenols in Plants: Isolation, Purification and Extract Preparation. Amsterdam: Elsevier Science (2014).

37. Ding S, Jiang H, Fang J. Regulation of immune function by polyphenols. $J$ Immunol Res. (2018) 2018:1264074. doi: 10.1155/2018/1264074

38. Zhou Y, Zheng J, Li Y, Xu DP, Li S, Chen YM, et al. Natural polyphenols for prevention and treatment of cancer. Nutrients. (2016) 8:8. doi: 10.3390/nu8080515

39. Mileo AM, Di Venere D, Linsalata V, Fraioli R, Miccadei S. Artichoke polyphenols induce apoptosis and decrease the invasive potential of the human breast cancer cell line MDA-MB231. J Cell Physiol. (2012) 227:33019. doi: $10.1002 /$ jcp. 24029

40. Visioli F, De La Lastra CA, Andres-Lacueva C, Aviram M, Calhau C, Cassano A, et al. Polyphenols and human health: a prospectus. Crit Rev Food Sci Nutr. (2011) 51:524-46. doi: 10.1080/10408391003698677

41. Dragan S, Andrica F, Serban MC, Timar R. Polyphenols-rich natural products for treatment of diabetes. Curr Med Chem. (2015) 22:14-22. doi: 10.2174/0929867321666140826115422

42. Wang S, Moustaid-Moussa N, Chen L, Mo H, Shastri A, Su R, et al. Novel insights of dietary polyphenols and obesity. J Nutr Biochem. (2014) 25:1-18. doi: 10.1016/j.jnutbio.2013.09.001

43. Ali F, Ismail A, Kersten S. Molecular mechanisms underlying the potential antiobesity-related diseases effect of cocoa polyphenols. Mol Nutr Food Res. (2014) 58:33-48. doi: 10.1002/mnfr.201300277

44. Magrone T, Russo MA, Jirillo E. Cocoa and dark chocolate polyphenols: from biology to clinical applications. Front Immunol. (2017) 8:677. doi: 10.3389/fimmu.2017.00677

45. Hossen MS, Ali MY, Jahurul MHA, Abdel-Daim MM, Gan SH, Khalil MI. Beneficial roles of honey polyphenols against some human 
degenerative diseases: a review. Pharmacol Rep. (2017) 69:1194-205. doi: 10.1016/j.pharep.2017.07.002

46. Bhullar KS, Rupasinghe HP. Polyphenols: multipotent therapeutic agents in neurodegenerative diseases. Oxid Med Cell Longev. (2013) 2013:891748. doi: 10.1155/2013/891748

47. Yamagata K, Tagami M, Yamori Y. Dietary polyphenols regulate endothelial function and prevent cardiovascular disease. Nutrition. (2015) 31:28-37. doi: 10.1016/j.nut.2014.04.011

48. Cardona F, Andres-Lacueva C, Tulipani S, Tinahones FJ, Queipo-Ortuno MI. Benefits of polyphenols on gut microbiota and implications in human health. J Nutr Biochem. (2013) 24:1415-22. doi: 10.1016/j.jnutbio.2013.05.001

49. Tap J, Furet JP, Bensaada M, Philippe C, Roth H, Rabot S, et al. Gut microbiota richness promotes its stability upon increased dietary fibre intake in healthy adults. Environ Microbiol. (2015) 17:4954-64. doi: 10.1111/1462-2920.13006

50. Macpherson AJ, Harris NL. Interactions between commensal intestinal bacteria and the immune system. Nat Rev Immunol. (2004) 4:478-85. doi: $10.1038 /$ nri1373

51. Pickard JM, Chervonsky AV. Intestinal fucose as a mediator of host-microbe symbiosis. J Immunol. (2015) 194:5588-93. doi: 10.4049/jimmunol.15 00395

52. Yang Y, Xu C, Wu D, Wang Z, Wu P, Li L, et al. gammadelta T cells: crosstalk between microbiota, chronic inflammation, and colorectal cancer. Front Immunol. (2018) 9:1483. doi: 10.3389/fimmu.2018.01483

53. Rescigno M. Intestinal microbiota and its effects on the immune system. Cell Microbiol. (2014) 16:1004-13. doi: 10.1111/cmi.12301

54. Biragyn A, Ferrucci L. Gut dysbiosis: a potential link between increased cancer risk in ageing and inflammaging. Lancet Oncol. (2018) 19:e295-e304. doi: 10.1016/S1470-2045(18)30095-0

55. Zitvogel L, Galluzzi L, Viaud S, Vetizou M, Daillere R, Merad M, et al. Cancer and the gut microbiota: an unexpected link. Sci Transl Med. (2015) 7:271ps1. doi: 10.1126/scitranslmed.3010473

56. Sheflin AM, Whitney AK, Weir TL. Cancer-promoting effects of microbial dysbiosis. Curr Oncol Rep. (2014) 16:406. doi: 10.1007/s11912-014-0406-0

57. Sun J, Kato I. Gut microbiota, inflammation and colorectal cancer. Genes Dis. (2016) 3:130-43. doi: 10.1016/j.gendis.2016.03.004

58. Jahani-Sherafat S, Alebouyeh M, Moghim S, Ahmadi Amoli H, GhasemianSafaei H. Role of gut microbiota in the pathogenesis of colorectal cancer; a review article. Gastroenterol Hepatol Bed Bench. (2018) 11:101-9.

59. Kawabata K, Yoshioka Y, Terao J. Role of intestinal microbiota in the bioavailability and physiological functions of dietary polyphenols. Molecules. (2019) 24:2. doi: 10.3390/molecules24020370

60. Ricciardiello L, Bazzoli F, Fogliano V. Phytochemicals and colorectal cancer prevention-myth or reality? Nat Rev Gastroenterol Hepatol. (2011) 8:592-6. doi: 10.1038/nrgastro.2011.149

61. Chow HH, Hakim IA. Pharmacokinetic and chemoprevention studies on tea in humans. Pharmacol Res. (2011) 64:105-12. doi: 10.1016/j.phrs.2011.05.007

62. Ju S, Ge Y, Li P, Tian X, Wang H, Zheng X, et al. Dietary quercetin ameliorates experimental colitis in mouse by remodeling the function of colonic macrophages via a heme oxygenase-1-dependent pathway. Cell Cycle. (2018) 17:53-63. doi: 10.1080/15384101.2017. 1387701

63. Farinetti A, Zurlo V, Manenti A, Coppi F, Mattioli AV. Mediterranean diet and colorectal cancer: a systematic review. Nutrition. (2017) 43-44:83-88. doi: 10.1016/j.nut.2017.06.008

64. Soldati L, Di Renzo L, Jirillo E, Ascierto PA, Marincola FM, De Lorenzo A. The influence of diet on anti-cancer immune responsiveness. J Transl Med. (2018) 16:75. doi: 10.1186/s12967-018-1448-0

65. Ostan R, Lanzarini C, Pini E, Scurti M, Vianello D, Bertarelli C, et al. Inflammaging and cancer: a challenge for the Mediterranean diet. Nutrients. (2015) 7:2589-621. doi: 10.3390/nu7042589

66. Hardy TM, Tollefsbol TO. Epigenetic diet: impact on the epigenome and cancer. Epigenomics. (2011) 3:503-18. doi: 10.2217/epi.11.71

67. Kroemer G, Zitvogel L. Cancer immunotherapy in 2017: the breakthrough of the microbiota. Nat Rev Immunol. (2018) 18:87-8. doi: 10.1038/nri. 2018.4
68. Nosrati N, Bakovic M, Paliyath G. Molecular mechanisms and pathways as targets for cancer prevention and progression with dietary compounds. Int $J$ Mol Sci. (2017) 18:10. doi: 10.3390/ijms18102050

69. Bhattacharyya S, Md Sakib Hossain D, Mohanty S, Sankar Sen G, Chattopadhyay S, Banerjee S, et al. Curcumin reverses T cell-mediated adaptive immune dysfunctions in tumor-bearing hosts. Cell Mol Immunol. (2010) 7:306-15. doi: 10.1038/cmi.2010.11

70. Zou T, Yang Y, Xia F, Huang A, Gao X, Fang D, et al. Resveratrol inhibits $\mathrm{CD} 4+\mathrm{T}$ cell activation by enhancing the expression and activity of Sirt1. PLoS ONE. (2013) 8:e75139. doi: 10.1371/journal.pone.0075139

71. Yao J, Wei C, Wang JY, Zhang R, Li YX, Wang LS. Effect of resveratrol on Treg/Th17 signaling and ulcerative colitis treatment in mice. World $J$ Gastroenterol. (2015) 21:6572-81. doi: 10.3748/wjg.v21.i21.6572

72. Ohno M, Nishida A, Sugitani Y, Nishino K, Inatomi O, Sugimoto M, et al. Nanoparticle curcumin ameliorates experimental colitis via modulation of gut microbiota and induction of regulatory T cells. PLoS ONE. (2017) 12:e0185999. doi: 10.1371/journal.pone.0185999

73. Hong EH, Heo EY, Song JH, Kwon BE, Lee JY, Park Y, et al. Transscirpusin A showed antitumor effects via autophagy activation and apoptosis induction of colorectal cancer cells. Oncotarget. (2017) 8:41401-11. doi: 10.18632/oncotarget.17388

74. Zhang Z, Wu X, Cao S, Cromie M, Shen Y, Feng Y, et al. Chlorogenic acid ameliorates experimental colitis by promoting growth of akkermansia in mice. Nutrients. (2017) 9:7. doi: 10.3390/nu9070677

75. Cui X, Jin Y, Hofseth AB, Pena E, Habiger J, Chumanevich A, et al. Resveratrol suppresses colitis and colon cancer associated with colitis. Cancer Prev Res. (2010) 3:549-59. doi: 10.1158/1940-6207.CAPR-09-0117

76. Churchill M, Chadburn A, Bilinski RT, Bertagnolli MM. Inhibition of intestinal tumors by curcumin is associated with changes in the intestinal immune cell profile. J Surg Res. (2000) 89:169-75. doi: 10.1006/jsre.2000.5826

77. Skyberg JA, Robison A, Golden S, Rollins MF, Callis G, Huarte E, et al. Apple polyphenols require $\mathrm{T}$ cells to ameliorate dextran sulfate sodiuminduced colitis and dampen proinflammatory cytokine expression. J Leukoc Biol. (2011) 90:1043-54. doi: 10.1189/jlb.0311168

78. Wang B, Wu C. Dietary soy isoflavones alleviate dextran sulfate sodiuminduced inflammation and oxidative stress in mice. Exp Ther Med. (2017) 14:276-82. doi: 10.3892/etm.2017.4469

79. Wagner AE, Will O, Sturm C, Lipinski S, Rosenstiel P, Rimbach G. DSS-induced acute colitis in C57BL/6 mice is mitigated by sulforaphane pre-treatment. J Nutr Biochem. (2013) 24:2085-91. doi: 10.1016/j.jnutbio.2013.07.009

80. Ramiro-Puig E, Perez-Cano FJ, Ramos-Romero S, Perez-Berezo T, Castellote C, Permanyer J, et al. Intestinal immune system of young rats influenced by cocoa-enriched diet. J Nutr Biochem. (2008) 19:555-65. doi: 10.1016/j.jnutbio.2007.07.002

81. Ma B, Khazali A, Wells A. CXCR3 in carcinoma progression. Histol Histopathol. (2015) 30:781-92. doi: 10.14670/HH-11-594

82. Abron JD, Singh NP, Murphy AE, Mishra MK, Price RL, Nagarkatti M, et al. Differential role of CXCR3 in inflammation and colorectal cancer. Oncotarget. (2018) 9:17928-36. doi: 10.18632/oncotarget.24730

83. Legitimo A, Consolini R, Failli A, Orsini G, Spisni R. Dendritic cell defects in the colorectal cancer. Hum Vaccin Immunother. (2014) 10:3224-35. doi: 10.4161/hv.29857

84. Malietzis G, Lee GH, Jenkins JT, Bernardo D, Moorghen M, Knight SC, et al. Prognostic value of the tumour-infiltrating dendritic cells in colorectal cancer: a systematic review. Cell Commun Adhes. (2015) 22:9-14. doi: 10.3109/15419061.2015.1036859

85. Kajihara M, Takakura K, Kanai T, Ito Z, Saito K, Takami S, et al. Dendritic cell-based cancer immunotherapy for colorectal cancer. World J Gastroenterol. (2016) 22:4275-86. doi: 10.3748/wjg.v22.i17.4275

86. del Corno M, Scazzocchio B, Masella R, Gessani S. Regulation of dendritic cell function by dietary polyphenols. Crit Rev Food Sci Nutr. (2016) 56:73747. doi: 10.1080/10408398.2012.713046

87. Deng Z, Rong Y, Teng Y, Mu J, Zhuang X, Tseng M, et al. Broccoliderived nanoparticle inhibits mouse colitis by activating dendritic cell AMP-activated protein kinase. Mol Ther. (2017) 25:1641-54. doi: 10.1016/j.ymthe.2017.01.025 
88. Del Corno M, Varano B, Scazzocchio B, Filesi C, Masella R, Gessani S. Protocatechuic acid inhibits human dendritic cell functional activation: role of PPARgamma up-modulation. Immunobiology. (2014) 219:416-24. doi: 10.1016/j.imbio.2014.01.007

89. Cavalcanti E, Vadrucci E, Delvecchio FR, Addabbo F, Bettini S, Liou R, et al. Administration of reconstituted polyphenol oil bodies efficiently suppresses dendritic cell inflammatory pathways and acute intestinal inflammation. PLoS ONE. (2014) 9:e88898. doi: 10.1371/journal.pone.0088898

90. De Santis S, Kunde D, Serino G, Galleggiante V, Caruso ML, Mastronardi $\mathrm{M}$, et al. Secretory leukoprotease inhibitor is required for efficient quercetinmediated suppression of TNFalpha secretion. Oncotarget. (2016) 7:75800-9. doi: 10.18632/oncotarget.12415

91. Ghattamaneni NKR, Panchal SK, Brown L. Nutraceuticals in rodent models as potential treatments for human Inflammatory Bowel Disease. Pharmacol Res. (2018) 132:99-107. doi: 10.1016/j.phrs.2018.04.015

92. Kaulmann A, Bohn T. Bioactivity of polyphenols: preventive and adjuvant strategies toward reducing inflammatory bowel diseases-promises, perspectives, and pitfalls. Oxid Med Cell Longev. (2016) 2016:9346470. doi: $10.1155 / 2016 / 9346470$

93. Guan G, Lan S. Implications of antioxidant systems in inflammatory bowel disease. Biomed Res Int. (2018) 2018:1290179. doi: 10.1155/2018/1290179

94. Lee CY, Nanah CN, Held RA, Clark AR, Huynh UG, Maraskine MC, et al. Effect of electron donating groups on polyphenol-based antioxidant dendrimers. Biochimie. (2015) 111:125-34. doi: 10.1016/j.biochi.2015.02.001

95. Kalaiselvan I, Samuthirapandi M, Govindaraju A, Sheeja Malar D, Kasi PD. Olive oil and its phenolic compounds (hydroxytyrosol and tyrosol) ameliorated TCDD-induced heptotoxicity in rats via inhibition of oxidative stress and apoptosis. Pharm Biol. (2016) 54:338-46. doi: 10.3109/13880209.2015.1042980

96. Gosslau A, En Jao DL, Huang MT, Ho CT, Evans D, Rawson NE, et al. Effects of the black tea polyphenol theaflavin-2 on apoptotic and inflammatory pathways in vitro and in vivo. Mol Nutr Food Res. (2011) 55:198-208. doi: 10.1002/mnfr.201000165

97. Zhang H, Tsao R. Dietary polyphenols, oxidative stress and antioxidant and anti-inflammatory effects. Curr Opin Food Sci. (2016) 8:33-42. doi: 10.1016/j.cofs.2016.02.002

98. Rodriguez-Ramiro I, Ramos S, Lopez-Oliva E, Agis-Torres A, Bravo L, Goya L, et al. Cocoa polyphenols prevent inflammation in the colon of azoxymethane-treated rats and in TNF-alpha-stimulated Caco-2 cells. $\mathrm{Br} \mathrm{J}$ Nutr. (2013) 110:206-15. doi: 10.1017/S0007114512004862

99. Rodriguez-Ramiro I, Ramos S, Bravo L, Goya L, Martin MA. Procyanidin B2 and a cocoa polyphenolic extract inhibit acrylamide-induced apoptosis in human Caco-2 cells by preventing oxidative stress and activation of JNK pathway. J Nutr Biochem. (2011) 22:1186-94. doi: 10.1016/j.jnutbio.2010.10.005

100. Sahu BD, Kumar JM, Sistla R. Fisetin, a dietary flavonoid, ameliorates experimental colitis in mice: relevance of NF-kappaB signaling. J Nutr Biochem. (2016) 28:171-82. doi: 10.1016/j.jnutbio.2015.10.004

101. Serra G, Incani A, Serreli G, Porru L, Melis MP, Tuberoso CIG, et al. Olive oil polyphenols reduce oxysterols -induced redox imbalance and proinflammatory response in intestinal cells. Redox Biol. (2018) 17:348-54. doi: 10.1016/j.redox.2018.05.006

102. Oz HS, Chen T, de Villiers WJ. Green tea polyphenols and sulfasalazine have parallel anti-inflammatory properties in colitis models. Front Immunol. (2013) 4:132. doi: 10.3389/fimmu.2013.00132

103. Saadatdoust Z, Pandurangan AK, Ananda Sadagopan SK, Mohd Esa N, Ismail A, Mustafa MR. Dietary cocoa inhibits colitis associated cancer: a crucial involvement of the IL-6/STAT3 pathway. J Nutr Biochem. (2015) 26:1547-58. doi: 10.1016/j.jnutbio.2015.07.024

104. Larrosa M, Gonzalez-Sarrias A, Yanez-Gascon MJ, Selma MV, AzorinOrtuno M, Toti S, et al. Anti-inflammatory properties of a pomegranate extract and its metabolite urolithin-A in a colitis rat model and the effect of colon inflammation on phenolic metabolism. J Nutr Biochem. (2010) 21:717-25. doi: 10.1016/j.jnutbio.2009.04.012

105. Owczarek K, Hrabec E, Fichna J, Sosnowska D, Koziolkiewicz M, Szymanski J, et al. Flavanols from Japanese quince (Chaenomeles japonica) fruit suppress expression of cyclooxygenase-2, metalloproteinase-9, and nuclear
factor-kappaB in human colon cancer cells. Acta Biochim Pol. (2017) 64:56776. doi: 10.18388/abp.2017_1599

106. Bucio-Noble D, Kautto L, Krisp C, Ball MS, Molloy MP. Polyphenol extracts from dried sugarcane inhibit inflammatory mediators in an in vitro colon cancer model. J Proteomics. (2018) 177:1-10. doi: 10.1016/j.jprot.2018.02.009

107. Hu Q, Yuan B, Xiao H, Zhao L, Wu X, Rakariyatham K, et al. Polyphenolsrich extract from Pleurotus eryngii with growth inhibitory of HCT116 colon cancer cells and anti-inflammatory function in RAW264.7 cells. Food Funct. (2018) 9:1601-11. doi: 10.1039/C7FO01794D

108. Aboura I, Nani A, Belarbi M, Murtaza B, Fluckiger A, Dumont A, et al. Protective effects of polyphenol-rich infusions from carob (Ceratonia siliqua) leaves and cladodes of Opuntia ficus-indica against inflammation associated with diet-induced obesity and DSS-induced colitis in Swiss mice. Biomed Pharmacother. (2017) 96:1022-35. doi: 10.1016/j.biopha.2017.11.125

109. Farombi EO, Adedara IA, Ajayi BO, Ayepola OR, Egbeme EE. Kolaviron, a natural antioxidant and anti-inflammatory phytochemical prevents dextran sulphate sodium-induced colitis in rats. Basic Clin Pharmacol Toxicol. (2013) 113:49-55. doi: 10.1111/bcpt.12050

110. Alabi QK, Akomolafe RO, Omole JG, Adefisayo MA, Ogundipe OL, Aturamu A, et al. Polyphenol-rich extract of Ocimum gratissimum leaves ameliorates colitis via attenuating colonic mucosa injury and regulating pro-inflammatory cytokines production and oxidative stress. Biomed Pharmacother. (2018) 103:812-22. doi: 10.1016/j.biopha.2018.04.071

111. Asensi M, Ortega A, Mena S, Feddi F, Estrela JM. Natural polyphenols in cancer therapy. Crit Rev Clin Lab Sci. (2011) 48:197-216. doi: 10.3109/10408363.2011.631268

112. Orlich MJ, Singh PN, Sabate J, Fan J, Sveen L, Bennett H, et al. Vegetarian dietary patterns and the risk of colorectal cancers. JAMA Intern Med. (2015) 175:767-76. doi: 10.1001/jamainternmed.2015.59

113. Halmos EP, Gibson PR. Dietary management of IBD-insights and advice. Nat Rev Gastroenterol Hepatol. (2015) 12:133-46. doi: 10.1038/nrgastro.2015.11

114. Fini L, Piazzi G, Daoud Y, Selgrad M, Maegawa S, Garcia M, et al. Chemoprevention of intestinal polyps in ApcMin/+ mice fed with western or balanced diets by drinking annurca apple polyphenol extract. Cancer Prev Res. (2011) 4:907-15. doi: 10.1158/1940-6207.CAPR-10-0359

115. Montrose DC, Horelik NA, Madigan JP, Stoner GD, Wang LS, Bruno RS, et al. Anti-inflammatory effects of freeze-dried black raspberry powder in ulcerative colitis. Carcinogenesis. (2011) 32:343-50. doi: $10.1093 /$ carcin/bgq248

116. Pan P, Skaer CW, Wang HT, Stirdivant SM, Young MR, Oshima K, et al. Black raspberries suppress colonic adenoma development in ApcMin/+ mice: relation to metabolite profiles. Carcinogenesis. (2015) 36:1245-53. doi: $10.1093 /$ carcin/bgv117

117. Ko JH, Sethi G, Um JY, Shanmugam MK, Arfuso F, Kumar AP, et al. The Role of resveratrol in cancer therapy. Int J Mol Sci. (2017) 18:12. doi: 10.3390/ijms18122589

118. McFadden RM, Larmonier CB, Shehab KW, Midura-Kiela M, Ramalingam $\mathrm{R}$, Harrison CA, et al. The role of curcumin in modulating colonic microbiota during colitis and colon cancer prevention. Inflamm Bowel Dis. (2015) 21:2483-94. doi: 10.1097/MIB.0000000000000522

119. Elbling L, Weiss RM, Teufelhofer O, Uhl M, Knasmueller S, SchulteHermann R, et al. Green tea extract and (-)-epigallocatechin-3-gallate, the major tea catechin, exert oxidant but lack antioxidant activities. FASEB J. (2005) 19:807-9. doi: 10.1096/fj.04-2915fje

120. Araujo JR, Goncalves P, Martel F. Chemopreventive effect of dietary polyphenols in colorectal cancer cell lines. Nutr Res. (2011) 31:77-87. doi: 10.1016/j.nutres.2011.01.006

121. Khan HY, Zubair H, Ullah MF, Ahmad A, Hadi SM. A prooxidant mechanism for the anticancer and chemopreventive properties of plant polyphenols. Curr Drug Targets. (2012) 13:1738-49. doi: 10.2174/138945012804545560

122. Mileo AM, Di Venere D, Miccadei S. Antitumour effects of artichoke polyphenols: cell death and ROS-mediated epigenetic growth arrest. Stem Cell Epigenet. (2016) 2016:3.

123. Khan HY, Zubair H, Faisal M, Ullah MF, Farhan M, Sarkar FH, et al. Plant polyphenol induced cell death in human cancer cells involves mobilization of intracellular copper ions and reactive oxygen species generation: a 
mechanism for cancer chemopreventive action. Mol Nutr Food Res. (2014) 58:437-46. doi: 10.1002/mnfr.201300417

124. Venancio VP, Cipriano PA, Kim H, Antunes LM, Talcott ST, MertensTalcott SU. Cocoplum (Chrysobalanus icaco L.) anthocyanins exert antiinflammatory activity in human colon cancer and non-malignant colon cells. Food Funct. (2017) 8:307-14. doi: 10.1039/C6FO01498D

125. Zitvogel L, Kepp O, Senovilla L, Menger L, Chaput N, Kroemer G. Immunogenic tumor cell death for optimal anticancer therapy: the calreticulin exposure pathway. Clin Cancer Res. (2010) 16:3100-4. doi: 10.1158/1078-0432.CCR-09-2891

126. Lee CS, Ryan EJ, Doherty GA. Gastro-intestinal toxicity of chemotherapeutics in colorectal cancer: the role of inflammation. World $J$ Gastroenterol. (2014) 20:3751-61. doi: 10.3748/wjg.v20.i14.3751

127. Golden EB, Apetoh L. Radiotherapy and immunogenic cell death. Semin Radiat Oncol. (2015) 25:11-7. doi: 10.1016/j.semradonc.2014.07.005

128. Steinman RM, Banchereau J. Taking dendritic cells into medicine. Nature. (2007) 449:419-26. doi: 10.1038/nature06175

129. Marin JJ, Sanchez de Medina F, Castano B, Bujanda L, Romero MR, Martinez-Augustin O, et al. Chemoprevention, chemotherapy, and chemoresistance in colorectal cancer. Drug Metab Rev. (2012) 44:148-72. doi: $10.3109 / 03602532.2011 .638303$

130. Redondo-Blanco S, Fernandez J, Gutierrez-Del-Rio I, Villar CJ, Lombo F. New insights toward colorectal cancer chemotherapy using natural bioactive compounds. Front Pharmacol. (2017) 8:109. doi: 10.3389/fphar.2017.00109

131. Yu Y, Kanwar SS, Patel BB, Nautiyal J, Sarkar FH, Majumdar AP. Elimination of colon cancer stem-like cells by the combination of curcumin and FOLFOX. Transl Oncol. (2009) 2:321-8. doi: 10.1593/tlo.09193

132. Patel BB, Sengupta R, Qazi S, Vachhani H, Yu Y, Rishi AK, et al. Curcumin enhances the effects of 5-fluorouracil and oxaliplatin in mediating growth inhibition of colon cancer cells by modulating EGFR and IGF-1R. Int J Cancer. (2008) 122:267-73. doi: 10.1002/ijc.23097

133. Aires V, Limagne E, Cotte AK, Latruffe N, Ghiringhelli F, Delmas D. Resveratrol metabolites inhibit human metastatic colon cancer cells progression and synergize with chemotherapeutic drugs to induce cell death. Mol Nutr Food Res. (2013) 57:1170-81. doi: 10.1002/mnfr.201200766

134. Abouzeid AH, Patel NR, Rachman IM, Senn S, Torchilin VP. Anticancer activity of anti-GLUT1 antibody-targeted polymeric micelles coloaded with curcumin and doxorubicin. J Drug Target. (2013) 21:994-1000. doi: 10.3109/1061186X.2013.840639

135. Jeng LB, Kumar Velmurugan B, Chen MC, Hsu HH, Ho TJ, Day CH, et al. Fisetin mediated apoptotic cell death in parental and Oxaliplatin/irinotecan resistant colorectal cancer cells in vitro and in vivo. J Cell Physiol. (2018) 233:7134-42. doi: 10.1002/jcp.26532

136. Shakibaei M, Mobasheri A, Lueders C, Busch F, Shayan P, Goel A. Curcumin enhances the effect of chemotherapy against colorectal cancer cells by inhibition of NF-kappaB and Src protein kinase signaling pathways. PLoS ONE. (2013) 8:e57218. doi: 10.1371/journal.pone.0057218

137. Hamaya Y, Guarinos C, Tseng-Rogenski SS, Iwaizumi M, Das R, Jover R, et al. Efficacy of adjuvant 5-fluorouracil therapy for patients with EMASTpositive stage II/III colorectal cancer. PLoS ONE. (2015) 10:e0127591. doi: 10.1371/journal.pone.0127591

138. Hakim L, Alias E, Makpol S, Ngah WZ, Morad NA, Yusof YA. Gelam honey and ginger potentiate the anti-cancer effect of 5-FU against HCT 116 colorectal cancer cells. Asian Pac J Cancer Prev. (2014) 15:4651-7. doi: 10.7314/APJCP.2014.15.11.4651

139. Snyder V, Reed-Newman TC, Arnold L, Thomas SM, Anant S. Cancer stem cell metabolism and potential therapeutic targets. Front Oncol. (2018) 8:203. doi: $10.3389 /$ fonc. 2018.00203

140. Kim TI. Chemopreventive drugs: mechanisms via inhibition of cancer stem cells in colorectal cancer. World J Gastroenterol. (2014) 20:3835-46. doi: 10.3748/wjg.v20.i14.3835

141. Munro MJ, Wickremesekera SK, Peng L, Tan ST, Itinteang T. Cancer stem cells in colorectal cancer: a review. J Clin Pathol. (2018) 71:110-6. doi: 10.1136/jclinpath-2017-204739

142. Shakibaei M, Buhrmann C, Kraehe P, Shayan P, Lueders C, Goel A. Curcumin chemosensitizes 5-fluorouracil resistant MMR-deficient human colon cancer cells in high density cultures. PLoS ONE. (2014) 9:e85397. doi: 10.1371/journal.pone.0085397

143. Nunez-Sanchez MA, Karmokar A, Gonzalez-Sarrias A, Garcia-Villalba $\mathrm{R}$, Tomas-Barberan FA, Garcia-Conesa $\mathrm{MT}$, et al. In vivo relevant mixed urolithins and ellagic acid inhibit phenotypic and molecular colon cancer stem cell features: a new potentiality for ellagitannin metabolites against cancer. Food Chem Toxicol. (2016) 92:8-16. doi: 10.1016/j.fct.2016. 03.011

144. Chen WS, Lee YJ, Yu YC, Hsaio $\mathrm{CH}$, Yen JH, Yu SH, et al. Enhancement of p53-mutant human colorectal cancer cells radiosensitivity by flavonoid fisetin. Int J Radiat Oncol Biol Phys. (2010) 77:1527-35. doi: 10.1016/j.ijrobp.2010.02.043

Conflict of Interest Statement: The authors declare that the research was conducted in the absence of any commercial or financial relationships that could be construed as a potential conflict of interest.

Copyright (c) 2019 Mileo, Nisticò and Miccadei. This is an open-access article distributed under the terms of the Creative Commons Attribution License (CC BY). The use, distribution or reproduction in other forums is permitted, provided the original author(s) and the copyright owner(s) are credited and that the original publication in this journal is cited, in accordance with accepted academic practice. No use, distribution or reproduction is permitted which does not comply with these terms. 